\title{
Appraising The Effectiveness Of Pipeline Interlinks In The Distribution Of Refined Petroleum Products In Nigeria.
}

\author{
Emmanuel Onwuka, Ph.D \\ Department of Marketing, Rivers State Polytechnics, \\ Bori, Rivers State, Nigeria \\ Onwubiko N. Dike, Ph.D \\ Department of Management Sciences, \\ Rhema University, Aba, Abia State, Niger
}

\begin{abstract}
This study attempted to appraise the effectiveness of pipeline interlinks in the distribution of refined petroleum products to the depots in Nigeria. The population of the study was 1468 comprising, Category A: Oil Marketers, 1258 (Major and Independent Marketers), Category B: Policy makers, 110 (Nigerian National Petroleum Corporation (NNPC) and Petroleum Products Pricing Regulatory Agency (PPPRA.), Category C: Pipeline and Products Marketing Company, 100 (PPMC). A sample size of 314 was drawn using Yamane (1964) formula. The sample size for each category was determined by the application of Bowley's proportional allocation formula. Primary and secondary data were accessed. In-depth interviews were held. The questionnaire was structured based on the five point Likert scale format. Opinions of marketing experts were used in the questionnaire validation. The scores derived from the pilot study were subjected to Cronbach Alpha technique and the reliability coefficient of the research instrument, 0.985 was determined. Using one way ANOVA statistical technique and Minitab software package, the hypothesis was tested at 0.05 level of significance and 9 degrees of freedom. The study revealed that the effectiveness of pipeline interlinks at $\mathbf{1 3 . 7 0}$ percent was non-significant for effective distribution of refined petroleum products to the depots across the country. Recommendations were made.
\end{abstract}

Keywords: Petroleum products, Pipeline interlinks, Distribution, Depots \& Refinery.

\section{BACKGROUND OF THE STUDY}

Petroleum is a mixture of hydrocarbon oils obtained below the sub-surface and generally occurs at depths of about 1,500 metres (Grend, 2001). It is the raw material around which a chain of commercial activities revolves. The marketing of petroleum products in Nigeria began in the early 19th century by Socony Vacuum Oil Company (predecessor of Mobil) which marketed sun flower kerosene. The Nigeria economy was supplied with petroleum products through imports by multinationals like Shell, Esso, among others, prior to the commissioning of the Old Port Harcourt Refinery in 1966. Shortly after the Nigerian Civil War in 1970, the nation witnessed an unprecedented explosion in the demand for petroleum products due to the expansion of economic activities (Grend, 2009). The production from this 35,000 barrels per day refinery became grossly inadequate to meet the demand. With the establishment of more refineries in Port-Harcourt, Warri and Kaduna which refined products at the capacity of 445,000 barrels per day, most petroleum products were now available locally. The eight major marketing companies, Mobil, African Petroleum, Total, Texaco, Oando, Agip, Conoil, Elf marketing and Independent Marketers completely controlled the distribution of refined petroleum products, among other activities (Ola, 1990). The increased domestic demand 
resulted in severe shortage of petroleum products and the private marketing companies could no longer match supply of the products with demand. After the nationwide acute shortage of petroleum products in 1973, government was compelled to venture into the products distribution to solve the ensuing problems and ease the suffering of the consumers. According to Grend (2009), the Federal Government of Nigeria constructed a network of pipelines and twenty storage depots all over the country. The main objective of the pipeline interlinks is to convey refined products from the products point (refinery) to the depots where the products can be lifted through bridging system (trucks, train and vessel) to enhance effective distribution. By 1995, a total of 4950 kilometers of pipelines of various diameters linking 20 storage depots to the refineries was constructed. Four "white" petroleum products namely, premium motor spirit (petrol), five star motor spirit, dual purpose kerosene and automotive gas oil (diesel) are handled by this transportation and storage system. The marketing companies purchase these products at Nigerian National Petroleum Corporation (NNPC) depots and distribute to their various filling stations. In addition to these depot and pipeline facilities, thirteen pump stations were located on the pipeline routes to facilitate regular supply of petroleum products. The extent to which the pipeline interlinks had contributed to regular supply of refined petroleum products to the depots across the country, constitutes the core of this study.

\section{Statement of the Problem}

Pipeline interlinks convey petroleum products from the point of produce to the depots across the country. Transportation of some oil derivatives is carried through pipelines. This type of transport has been proved to be reliable and economic over time (Sullen, et al 2010). Amu (1990) noted that pipeline construction nation-wide effectively increased product storage capacity from 0.18 to 1.83 million metric tons estimated as 90 days national requirement. Sometimes, petroleum products are imported to supplement local refineries supply for the country's needs. Refined petroleum products are then received by Pipelines and Products Marketing Company Limited (PPMC) from the refineries at the ports for transportation through pipelines to the depots all over the country from where petroleum products marketers collect by road tankers to retail outlets. Adebowale (1996) disclosed that for several years now, the fuel scarcity has remained a frequent and acute problem in Nigeria. Petroleum Dealers Association of Nigeria in 1996, noted that over the previous years there has hardly been a six month reprieve without one incidence of acute fuel scarcity, sometimes each lasting several days with its attendant disruption of basic services in the country. Fuel scarcity has been a thorn in the flesh of the citizens of Nigeria, coupled with its adverse effects resulting from accidents (industrial and domestic) to waste of man hour. There has been an epileptic nature of petroleum product supply and distribution. Agba (1991) identified pipeline related problems as being responsible for fuel scarcity situation in Nigeria. He noted certain "bottlenecks" (pipeline related problems), which are essentially logistic in nature affect the capacity utilization of the existing petroleum pipeline system. Local production of petroleum products fall short of meeting the internal consumption of the nation as a result of low capacity utilization, gross mismanagement, exclusive unit operating cost and bloated overheads costs, intolerable process losses, sabotage and inadequate technological input or necessary product and process upgrade (Nwachukwu, 2007).With over 4950 kilometers of pipelines of various diameters linking 20 storage depots to the refineries across the country and the huge financial resources invested in the project, scarcity of refined petroleum products still persisted in Nigeria. The study sought to investigate the extent to which the pipeline interlinks had contributed to effective distribution of refined petroleum products in tandem with the prime objectives of the pipeline project. 


\section{Objective of the Study}

The study has the broad objective of assessing the effectiveness of the pipeline interlinks in the distribution of refined petroleum products to the depots in Nigeria. The specific objective was to determine the extent to which pipeline interlinks are effective in distributing refined petroleum products to the depots across the country.

\section{Research Question}

How effective are the pipeline interlinks in the distribution of refined petroleum products to the depots across the country?

\section{Delimitation of the Study}

The study was limited to the senior staff of the Petroleum Resources Ministry, Nigerian National Petroleum Corporation (NNPC), Petroleum Products Pricing Regulatory Agency (PPPRA), Major and Independent Marketers, Pipeline and Products Marketing Company (PPMC) within the Salary Grade Level 9-17.

\section{Hypothesis Formulation}

At 0.05 significance level and 9 degrees of freedom, the study hypothesis was formulated and tested; HO: The pipeline interlinks are not significantly effective in the distribution of refined petroleum products to the depots across the country. H1: The pipeline interlinks are significantly effective in the distribution of refined petroleum products to the depots across the country.

\section{REVIEW OF RELATED LITERATURE}

Soyode (2001) defined the downstream segment as comprising all other activities following delivery to processing plants. The activities include refining of crude oil into white petroleum products and subsequent conversion to petrochemical products. The basic responsibility of refinery is to ensure that crude oil is converted into finished product required by the market in the most efficient and profitable manner. The full petroleum products from the refineries consist of liquefied petroleum gas (cooking gas),premium motor spirit (petrol),dual purpose kerosine (aviation fuel and household kero), automative gas oil (diesel),low and high pour fuel oil, waxes ( three grades),base oils, asphalt and sulphur. The downstream operations involve the importation of white and other finished products, storage of white products in depots, transportation and distribution through pipelines or bridging by long distance trucks, marketing, pump delivery to consumers and users in cars and cans, tail-retailing in gallons, bottles, and quarts. There are two ways by which petroleum products can be distributed viz: pipeline and bridging systems. The pipeline system conveys the petroleum products from the refinery to the depots. The pipeline may be surface or underground. For instance, Adubi (1995) stated that there are five basic pipeline systems in Nigeria referred to as Systems 2A, 2B, 2C, 2D, and 2E and additional four Sub Systems namely, Systems 2AX, 2CX, 2DX and 2EX.While pipeline System 2A runs from Warri through Benin depots and terminates at Mosimi depot, System 2EX originates at Port Harcourt and runs through Aba-Enugu depot up to Markurdi (parallel to System 2E) and then proceeds to terminate at Yola depot. System 2C (crude oil line) runs from Escravos through Warri, Abudu, Auchi, Lokoja, Abaji, Izoo and Sarkin Pawa to terminate at Kaduna.System 2CX starts from Enugu, crosses the River Niger to Auchi, proceeds to Suleja with a spur to Minna depot and then terminates in Kaduna. The bridging system involves conveying petroleum products from the depots to filling stations, outlets, jetty and other retail points. The importance of depot in the storage and distribution of petroleum products in Nigeria cannot be over emphasized. Depot marks the end point of products origin 
from where major and independent marketers evacuate the products using trucks, tankers and vessels to various parts of the country where pipeline did not cover. According Marinho (1985), bridging of white products would virtually stop when the whole country is covered with pipeline interlink system. This will save the nation enormous transportation cost, as well as the wear and tear on the high way infrastructure (road). Ehikwe (2002) maintained that pipeline transportation system is very rigid and inflexible as one movement must terminate at destination point without stoppage or reversal. According to him the system consists of the materials used in laying the pipes, the products carried, operational services, various accessories such as taps, cocks, stoppers, elbows, joints, flow meters, gauges, hoses, location factors and guiding regulations, control of the use of pipeline transport. It will be difficult to discuss depot without the refinery. Depot on itself cannot be effective except products are pumped into them via pipeline running from the refinery. The economic advantage of the depot is so much to any nation, company and organization where products have to pass through pipelines. Ehikwe(2002) noted that pipelines are more economical when the products are in sufficient quantity and there are large population of consumers. Though pipeline interlinks serve as the modern transportation system in conveying petroleum products, accidents are minimal but inevitable especially where pipes are old and require replacement, interference by persons of questionable intentions, bursts resulting from exertion of high pressure, leakages, damages by rust of pipes, landslides and erosion that could expose the laid and buried pipes. Such operational constraints like pipeline stoppages, movement of batches through many areas/pipelines, use of preferential routes to avoid contamination losses, onpick demand hours of pumping, local constraints, reversions of flow direction, and surge tank operations affect the performance of the pipeline system. In view of the aforementioned challenges, this study was an attempt at appraising the effectiveness of pipeline interlinks in the distribution of refined petroleum products to the depots across the country to ease the suffering of the consumers.

\section{METHODOLOGY}

The research design was survey. The population of study was 1468, comprising Oil Marketers (Major and Independent Marketers, Category A; 1258), Policy Makers (Petroleum Resources Ministry, Petroleum Products Price Regulatory Agency, PPPRA, CategoryB; 110), Pipeline and Products Marketing Company (PPMC, Category C; 100).The sample size of 314 was determined using Yamane (1967) formula. Applying Bowley's proportional allocation formula, the sample size for each category of the respondents was estimated, viz, A (269), B (24) and C (21).Primary and secondary sources were accessed for data. The questionnaire adopted the five point Likert Scale format, viz, Strong Agree (5points), Agree (4points), Undecided (3points), Disagree (2points) and Strongly disagree(1point) with the aggregate mean of 3.0.The instrument was validated using the opinions of marketing experts. Pilot study was carried out. The reliability coefficient of the research instrument was estimated to be 0.985 using Cronbach's Alpha technique. The hypothesis of the study was formulated and tested at 0.05 level of significance and 9 degrees of freedom, using one-way ANOVA and Minitab software package. The Minitab software technique was applied to determine the extent of the effectiveness of pipeline interlinks in the distribution of petroleum products to depots across the country.

\section{DATA PRESENTATION AND ANALYSES}

The data obtained from the study were presented as shown on the next page. 
Table 4.1. Distribution of Questionnaires.

\begin{tabular}{|c|c|c|c|c|c|c|}
\hline $\begin{array}{l}\text { Category of } \\
\text { Respondents }\end{array}$ & $\begin{array}{l}\text { Number } \\
\text { distributed }\end{array}$ & $\begin{array}{l}\text { Number } \\
\text { not returned }\end{array}$ & $\begin{array}{l}\text { Number } \\
\text { returned }\end{array}$ & $\begin{array}{l}\text { Number } \\
\text { rejected }\end{array}$ & $\begin{array}{l}\text { Number } \\
\text { Accepted }\end{array}$ & $\begin{array}{l}\text { Percentage } \\
\text { Accepted }\end{array}$ \\
\hline $\begin{array}{ll}\text { A: } & \text { Oil } \\
\text { Marketers } & \\
\end{array}$ & 1258 & 98 & 1160 & 28 & 1132 & 86 \\
\hline $\begin{array}{l}\text { B: Policy } \\
\text { Makers }\end{array}$ & 110 & 8 & 102 & 4 & 98 & 7 \\
\hline $\begin{array}{l}\text { C:Senior Staff } \\
(\mathrm{PPMC})\end{array}$ & 100 & 9 & 91 & 3 & 88 & 7 \\
\hline TOTAL & 1468 & 115 & 1353 & 35 & 1318 & 100 \\
\hline
\end{tabular}

Source: Field Survey, 2014.

Table 4.1 showed that a total of 1468 copies of questionnaires was distributed, 1353 were returned ,representing 92.0 percent while 115 were not returned (8.0percent).Of the 1353 returned questionnaires,35 were rejected (2.5percent) due to discrepancies while 1318, representing (97.5percent) were utilized .

Table 4.2 Analysis of Responses for Effectiveness of Pipeline interlinks in Petroleum Products Distribution

\begin{tabular}{|c|c|c|c|c|c|c|c|}
\hline ltem & $\begin{array}{l}\text { Number of } \\
\text { Respondents } \\
\text { Agree, A }\end{array}$ & $\begin{array}{l}\text { Scores of } \\
\text { Respondents } \\
\text { Agree, A }\end{array}$ & $\begin{array}{l}\text { Number of } \\
\text { Respondents } \\
\text { Disagree, D }\end{array}$ & $\begin{array}{l}\text { Scores of } \\
\text { Respondents } \\
\text { Disagree, D }\end{array}$ & $\begin{array}{l}\text { Total number of } \\
\text { Respondents }(A+D)\end{array}$ & $\begin{array}{l}\text { Scores of } \\
\text { resp. D }\end{array}$ & $\begin{array}{l}\text { Percent } \\
\text {-D }\end{array}$ \\
\hline 1 & 795 & 1585 & 523 & 1041 & 1318 & 518 & 39.60 \\
\hline 2 & 801 & 1328 & 517 & 760 & 1318 & 243 & 31.56 \\
\hline 3 & 708 & 1034 & 610 & 837 & 1318 & 227 & 41.00 \\
\hline 4 & 638 & 817 & 680 & 902 & 1318 & 222 & 55.36 \\
\hline 5 & 652 & 857 & 666 & 886 & 1318 & 220 & 51.77 \\
\hline
\end{tabular}

Source: Field Survey, 2014

\section{Test of Hypothesis}

Ho: The pipeline interlinks are not significantly effective in the distribution of refined petroleum products to the depots across the country.

H1: The pipeline interlinks are significantly effective in the distribution of refined petroleum products to the depots across the country.

Welcome to Minitab, press F1 for help.

One-way ANOVA: Scores Agree A, Scores Disagree D.

$\begin{array}{llrrrr}\text { Source } & \text { DF } & \text { SS } & \text { MS } & \text { F } & \text { P } \\ \text { Factor } & 1 & 142803 & 142803 & 2.43 & 0.158 \\ \text { Error } & 8 & 470330 & 58791 & & \\ \text { Total } & 9 & & & & \\ \text { S }=242.5 & \text { R-Sq }=23.29 \% & \text { R-Sq (adj) }=13.70 \%\end{array}$

Source: Field Survey, 2014. 
The result of the hypothesis test showed that F-critical (5.318) was greater than F-calculated (2.43) at 9 degrees of freedom and 0.05 level of significance. The p-value, 0.158 was greater than 0.05 (i.e, p>0.05). In applying the decision rule, the null hypothesis (Ho) was accepted and the alternate hypothesis (H1) was rejected. The co-efficient of determination, R2 (adj) was 13.70 percent. This result showed that the extent to which pipeline interlinks distributed refined petroleum products to the depots across the country to be 13.70 percent. In conclusion, the effectiveness of pipeline interlinks in the distribution of refined petroleum products to various depots across the country was therefore non-significant for effective distribution.

\section{DISCUSSION OF FINDINGS}

The result of the study revealed the pipeline interlinks were significantly ineffective in the distribution of refined petroleum products to the depots across the country. Nwachukwu (2003), in his study corroborated this result when he stated that the petroleum pipeline system in the country was grossly underutilized. He attributed the low level of utilization to poor and inadequate production rates in the nation's refineries. It was also certain that pipeline cannot be effective and efficient without the product passing through it. By implication, the efficiency of distributing petroleum products through pipeline grossly depends on the effectiveness of the refinery.The study confirmed that the petroleum pipeline system was designed to meet known and predicated demand in some part of the country (Agba ,1996). But the pipeline system which does not cover the whole nation is not likely to have maximum effect on the citizenry. Adubi (1995) and Marinho (1985) also confirmed the result of this study. They maintained that when the nation's refineries were at full production capacity, products evacuation by pipeline was $70 \%$ and the remaining $30 \%$ by sea, road and rail. The researchers argued that since the pipeline interlinks did not cover all the areas and even if they covered, the refineries lacked the capacity to put the pipelines into full use. Amino (1990) attributed the ineffectiveness of the petroleum pipeline interlinks to smuggling, bunkering and vandalization of pipelines. Nwachukwu (2003), noted that scarcity of petroleum products in Nigeria could also result from pipeline damages, sabotage, breakdown, leakage and prolonged routine maintenance.

\section{Implications of findings}

With effective pipeline interlinks, products evacuation is bound to increase substantially and impact significantly on the release of jetty occupancy time for black products evacuation, especially at Warri and Port Harcourt refineries. This will enable the refineries operate with more stability, effectiveness and reliability. Bridging of white petroleum products would virtually stop and trucks freed from South - North routes. The wear and tear on the nation's highway infrastructures would be drastically reduced.

\section{CONCLUSION}

Government's decision in 1975 to construct products distribution pipelines over a wide expanse of the territory of Nigeria brought the nation into the modern era in this vital sector of the energy industry. With the coming on stream of the pipeline interlinks, the crippling widespread petroleum products shortages experienced in the country ought to have become history. But the nation is confronted with petroleum products scarcity from time to time. The study revealed that the effectiveness of pipeline interlinks in the distribution of petroleum products across the country was insignificant. This is partly because the concentration of the oil pipelines was mainly in urban cities. Onwuka (2014) opined that pipeline related problems are not the major causes of frequent fuel scarcity. For the pipeline system to continue to play strategic role in petroleum products distribution, its present level of utilization must be increased in line with national energy demand. This provides for hitch- free distribution of 
petroleum products and saves the nation enormous transportation costs, as well as the wear and tear on the high way infrastructure (road). Adubi(1995) noted that the evolution of independent marketers was made possible by the actualization of the pipeline and depots projects which brought petroleum products to the doorsteps of all Nigerians for the first time. Prior to that time evacuation from the refineries was primarily by trucks. In return the independent marketers, who now number more than one thousand two hundred and fifty, have provided a rapid increase in the number of filling stations in all corners of Nigeria. This is one of the positive impacts that the pipeline interlinks have made on petroleum products distribution in Nigeria.

\section{RECOMMENDATIONS}

1. Since pipeline distribution of petroleum products is one of the safest and cost effective means of conveying refined petroleum products from the refinery to the depots. More pipeline interlinks should be constructed round the country, especially in the hinter lands. Government should extend or embark on the expansion of the existing oil pipelines to cover all the local government headquarters in the country. This project has an overall effect of smoothening petroleum products distribution throughout the country. It makes the effectiveness of pipeline system felt more by the end users and reduce illegal bunkering and products adulteration with its attendant risks to life and properties.

2. The pipeline interlinks cannot be effective without the petroleum products passing through them. To operate at optimal capacities, the turn-around-maintenance of the nation's refineries should be carried out regularly, at least every two years. When the refineries are fully restored, production will increase and the petroleum products pipelines will operate at full capacity.

3. Special oil pipes with fire and acid resistance features should be used to replace the vulnerable pipeline system as to forestall vandalization.

\section{Reference}

Adebowale, Y. (1996) "Oil woes a four year record of fuel scarcity shows a worsening crisis in Nigeria” News watch Magazine, July 15:10

Adubi, F. A. (1995). The Impact of Pipeline Interlink on the Distribution of Refined Petroleum products in Nigeria, Kaduna, Abuja: NNPC press.

Agba, E.E (1991) "Efficient distribution of petroleum products"

The financial post, 6(2):23

Amu, L. (1990). A Review of Nigeria's Oil Industry. Lagos: NNPC press

Ehikwe, A. E. (2002). Transportation and Distribution Management Enugu: precision publishers Ltd

Grend, M. D. (2009) Petroleum supply and Distribution Port Harcourt: Royal publication.

Marinho, F. R. A. (1985) Nigeria, a Regenerative Economy or Vegetative Existence?, Ibadan, NNPC

Nwachukwu, M.U. (2007) "The effectiveness of petroleum products supply and distribution in Enugu State Nigeria" Journal of scientific and industrial studies 5(1):78-82

Nwachukwu, M.U (2003) “The impact of pipeline related problems on petroleum products distribution in Nigeria" Environmental studies and research Journal 3(1): 7-16.

Nwachukwu, M.U. (2003) "The efficiency of petroleum pipeline system in south western Nigeria and its relationship to fuel scarcity" Environmental studies and research journal 5 (2):138-147.

Ola, A. (1990). Oil and Oil Refinery Environment, Port-Harcourt, NNPC press. 
Onwuka, E., \& Dike, O. N. (2015). Appraising the effectiveness of Pippeline Interlinks in the Distribution of Refined Petroleum Products in Nigeria. Advances in Social Sciences Research Journal, 2(5) 181-188

Onwuka, E. (2014) "Pipeline and Products Marketing of Petroleum Products in A Regulated Downstream Sector in Nigeria.” An unpublished Ph.D Degree Thesis. University of Nigeria, Nsukka, February.

Soyode, G.A. (2001) “Deregulation of the downstream sector: matters arising” NESG Economic indicators 7(2):5560.

Sullen N. R, Leandro, M., William, M. B., Flavio, N-Jr., Lucia, V. R.A., Ana, P.F.D,

Barbosa, P. and Susana, R. (2010) "An operational scheduling Model to production distribution through a pipeline network" American Chemical

Society $2010(49) 5661-5682$ 